\title{
Sucedâneo nas fases inicial e de crescimento para tamanduá-bandeira (Myrmecophaga tridactyla)
}

BRAZ, Jordana G. ${ }^{1}$; VIEIRA, Ananda S. ${ }^{2}$; RIBEIRO, Karen R. ${ }^{2}$; SANTOS, Ana Paula R. S. ${ }^{1}$; BIANCHINI, Mateus A.2; MORGADO, Thais $O .^{3}$

1 Graduandas em Medicina Veterinária, FAVET, UFMT.

${ }^{2}$ Residentes em Medicina de Animais Selvagens do Programa de Residência Uniprofissional em Medicina Veterinária, HOVET, UFMT.

${ }^{3}$ Veterinária do Zoológico da UFMT.

E-mail: jordanapgomide@hotmail.com

RESUMO: Os tamanduás bandeira (Myrmecophaga tridactyla) são animais com ampla distribuição no território brasileiro. Com a redução de seu habitat natural pela expansão humana, esses animais se tornaram vítimas de grandenúmero de acidentes em estradas e zonas urbanas, transformando a entrega de filhotes órfãos uma ocorrência comum no Hospital Veterinário da UFMT. O trabalho tem por finalidade descrever a formulação de dois sucedâneos para três filhotes de tamanduá atendendo as exigências calóricas da espécie. A alimentação artificial foi desenvolvida com ingredientes especiais, visando suprir as necessidades nutricionais nas duas etapas preliminares da vida a partir de duas dietas. A primeira a base de leite de cabra em pó integral, sucedâneo comercial para felinos domésticos, ovo cozido sem casca e fibra comercial em pó. E a segunda composta por leite zero lactose, sucedâneo comercial para desmame de felinos domésticos, ovo cozido sem casca e frutas. Apresentando resultados promissores quanto ao desenvolvimento ponderal dos filhotes.

Palavras-chave: alimentação artificial; filhotes; pilosa; suplementação; taurina; vitamina $\mathrm{K}$.

\section{INTRODUÇÃO}

O tamanduá bandeira
(Myrmecophaga tridactyla) é um mamífero terrestre, de hábito solitário e atividade crepuscular-noturna, que possui adaptações anatômicas, comportamentais e fisiológicas específicas para o consumo de formigas, cupins, suas larvas e ovos e de larvas de besouros. Suas garras dianteiras, além da autodefesa, são apropriadas para abertura de formigueiros e cupinzeiros, o longo focinho comporta uma língua alongada e portátil, não possuem dentes, contudo suas glândulas salivares bem desenvolvidas secretam uma saliva espessa que tem papel importante na captação e digestão do alimento (NOWAK; PARADISO, 1983; MIRANDA, 2012).

Contudo, fatores de transformações ou perda do habitat implicam em alterações na disponibilidade de alimento, atropelamento, incêndios florestais, caça predatória e doenças infecciosas contribuindo para o declínio da população de tamanduás (MIRANDA, 2014), justificando seu status vulnerável de conservação. De acordo com Miranda (2012) a causa do grande número de atropelamentos é consequente do andar letárgico que os tornam alvos fáceis para motoristas 
distraídos em alta velocidade. Fêmeas gestantes ou lactantes, quando acometidas, parecem ser mais prejudicadas, uma vez que seu período de gestação é de 190 dias e a amamentação dura de 6 a 9 meses.

Órfãos de tamanduá-bandeira podem existir por diversos fatores como abandono do neonato pela mãe, tanto em cativeiro como em vida livre e outros fatores que ocasionem a morte apenas da mãe como queimadas, atropelamento e caça (MIRANDA, 2012). Em cidades situadas nos biomas de ocorrência desta espécie é comum a chegada de filhotes órfãos em hospitais veterinários e zoológicos com históricos semelhantes aos citados acima.

Assim como em outras espécies, neonatos e filhotes precisam de cuidados médicos principalmente relacionados à manutenção da temperatura corpórea, glicemia e hidratação. Todavia o cuidado de filhotes de tamanduá exige do veterinário 0 conhecimento das particularidades da espécie como hábito alimentar, exigências nutricionais e comportamento (COSTA, 2007). Na prática diária, observamos que grande parte dos distúrbios clínicos apresentados por tamanduás bandeira são atribuídos a distúrbios nutricionais. Porém, mesmo constatando tal fato, fornecê-los uma dieta que supra adequadamente suas necessidades nutricionais é comumente uma tarefa desafiadora, uma vez que tais necessidades ainda não foram empiricamente determinadas (CLARK et al., 2016).

O objetivo desse trabalho é descrever a formulação de dois sucedâneos para três filhotes de tamanduá bandeira ( $M$. tridactyla) atendendo as necessidades calóricas da espécie.

\section{MATERIAL E MÉTODOS}

Foram recebidos no Setor de Animais Selvagens do Hospital Veterinário (HOVET) da Universidade Federal de Mato Grosso (UFMT) três filhotes de tamanduá-bandeira $(M$. tridactyla), duas fêmeas e um macho, em um intervalo de 43 dias. Todos com histórico de atropelamento da mãe, resgatados pela Policia Militar Ambiental do estado de Mato Grosso em rodovias nos municípios de Paranatinga e Várzea Grande. Estes pesavam $1,4 \mathrm{~kg}$ (Tamanduá 1), 2kg (Tamanduá 2) e $2,1 \mathrm{~kg}$ (Tamanduá $3-$ Macho), respectivamente. Ao exame físico, os Tamanduás 2 e 3 apresentavamescore de condição corporal dois (numa escala de um a cinco) com evidenciação óssea e algumas pequenas escoriações. $O$ Tamanduá 1 apresentava bom estado geral, presença decoto umbilical, além de tungíase. Todos estavam parasitados por carrapatos e com abdômen distendido. De acordo com o histórico, os tamanduás 2 e 3 eram alimentados com iogurte natural antes de serem encaminhados ao HOVET, já o tamanduá 1 foi encaminhado diretamente ao hospital.

Para cada indivíduo foi manipulada uma dieta balanceada com base no cálculo de exigência energética e determinada a capacidade estomacal. $\mathrm{O}$ cálculo de exigência energética consistiu na equação de adaptada: $70 \times\left(\right.$ peso em kg) ${ }^{0,75} \times 0,70 \times \mathrm{K}=$ quilocalorias/dias; no qual o valor 0,70 representa $70 \%$ da energia de um mamífero placentário, a constate $\mathrm{K}$ utilizada foi de 5 (2 valor de taxa de manutenção e 3 de taxa de crescimento) (CONGRESSO DA SZB, 2015).. A capacidade estomacal foi extrapolada pela de mamíferos que é de 25 a $50 \mathrm{~mL} / \mathrm{kg}$ por peso corporal (COSTA, 2007), para assim estabelecer o volume ingerido e a frequência de amamentações por dia. Os ingredientes eram incorporados gradualmente a dieta do filhote. 
A primeira dieta (Dieta 1) manipulada foi 10 gramas de leite de cabra em pó, 15 gramas de sucedâneo comercial para felinos domésticos (Support Milk Catß) e 1,3 gramas de mix de fibras em pó, diluído em $80 \mathrm{~mL}$ de água filtrada e 45 gramas de ovo cozido sem casca. Os níveis nutricionais foram calculados com auxílio de planilha no Excel baseado nos níveis de garantia dos produtos, expressos em a matéria seca: Proteína Bruta (PB) 41,81\%; Energia Metabolizável 182,94 Kcal; Gorduras totais 32,62\%; Fibra Bruta 5,27\%; Cálcio (Ca) 0,76\%; Fósforo (P) $0,52 \%$ e relação $\mathrm{Ca:} P$ de 1,46 . Todos esses ingredientes foram misturados no liquidificador até tornarem uma consistência líquida, posteriormente peneirada, para assim ser oferecido emmamadeira ao filhote. Esta dieta foi oferecida apenas ao tamanduá 1, em 30 $\mathrm{ml}$ de quatro a cinco vezes por dia.

A segunda dieta (Dieta 2) era composta de 106 gramas de leite sem lactose, 20 gramas de sucedâneo comercial para felinos domésticos em desmame (Support Papinha Cat $(B), 60$ gramas de ovos cozidos sem casca e 57 gramas de mamão sem casca e sementes garantindo os seguintes níveis nutricionais na matéria seca, calculados conforme supracitado: Proteína Bruta (PB) 37,03\%; Energia metabolizável 618,82 Kcal; Gorduras totais 20,86\%; Fibra Bruta 3,95\%; Cálcio (Ca) 0,90\%; Fósforo (P) 0,71\% e relação $\mathrm{Ca}: \mathrm{P}$ de 1,25 . Os tamanduás 2 e 3 receberam apenas essa dieta com volume inicial de $40 \mathrm{~mL}$. Entretanto a primeira dieta do tamanduá 1 foi substituída pela dieta 2 com o mesmo consumo, sendo fornecida em potes, conforme a consistência do alimento e o ganho de peso, de quatro a cinco vezes ao dia. Além disso, o peso do animal era mensurado a cada 15 dias e de acordo com isso o volume de alimento fornecido era aumentado. Para os três filhotes eram fornecidas ainda suplementações vitamínicas e minerais à parte da alimentação, de maneira empírica extrapolando-se de cães domésticos.

\section{RESULTADOS E DISCUSSÃO}

A incidência de atropelamentos de fêmeas em época de procria aumenta o número de filhotes órfãos, que necessitam de cuidados veterinários, especialmente nutricionais. São poucos os estudos quanto às exigências nutricionais da ordem Pilosa, contudo sabe-se de deficiências específicas de determinadas vitaminas e aminoácidos (MIRANDA, 2012)

Os tamanduás são animais letárgicos, possuindo uma taxa de metabolismo comparativamente menor à dos demais mamíferos eutherianos. Sua demanda energética é de $347 \mathrm{~kJ}$ $\mathrm{DE} / \mathrm{kg}^{0,75} / \mathrm{dia}$, em que DE representa energia digerível, é bem menor do que os 460-580 kJ DE/kg 0,75/dia encontrado em cães e demais mamíferos. Ressaltando que foi demonstrada uma redução da necessidade energética de manutenção com o decorrer da idade (STAHL et al., 2012). A capacidade estomacal extrapolada pelo de outros mamíferos observou que o volume inicial aproximado mais adequado para estes animais foi de $30 \mathrm{~mL} / \mathrm{kg}$.

Segundo Miranda (2012) o leite de cabra é recomendado para as 6 primeiras semanas de vida, quando o volume consumido ainda é pequeno. Este é vantajoso em relação ao leite de vaca sem lactose devido a sua gordura de maior digestibilidade (COSTA, 2007). Com isso o leite de cabra proporciona maior energia ao recém-nascido que pode estar em convalescença. Outra razão para tal, foi a aceitação do leite de cabra pelo tamanduá 1, tornando assim a troca pela dieta 2 após aproximadamente três meses (Figura 1).

Pelo fato dos tamanduás 2 e 3 já possuírem idade estimada acima de 6 
semanas, foi fornecida a dieta 2, composta de leite sem lactose (Figura 2).A escolha do leite vai depender da sua palatabilidade e da sua digestibilidade, que pode variar entre os indivíduos, que mesmo tendo dietas adequadas podem apresentar alterações gastrointestinais (COSTA, 2007).

Apesar de seus outros componentes, o sucedâneo para felinos domésticos é de escolha devido à presença da taurina, um aminoácido sulfurado encontrado livre no coração, na retina, na musculatura esquelética e no cérebro. Este é produzido na maioria dos mamíferos, exceto os felinos, em quantidades suficientes no fígado a partir de metionina e cisteína, por meio da enzima decarboxilase do ácido cistéicosulfínico (CARCIOFI; OLIVEIRA, 2007). Um estudo recente demonstrou que os tamanduás conseguem sintetizar a taurina a partir de amino-ácidos sulfúricos dependendo da quantidade adequada destes (NOFS etal., 2016).Além disso, o sucedâneo para desmame de felinos foi utilizado por proporcionar consistência mais pastosa ao alimento, facilitando o consumo da dieta em potes para os tamanduás 2 e 3.

As fontes de proteínas utilizadas para tamanduás em cativeiros são diversas, como carne bovina, carne de rã, ração para cães ou gatos e até ovo cozido (MIRANDA, 2014). Dentre esses, o ovo é a fonte de baixo custo e geralmente tem boa aceitação por filhotes, descartando a necessidade do uso de outros produtos de origem animal.

Em um estudo, no qual foi feito a ordenha de três tamanduás lactantes, as amostras obtidas demonstraram níveis de proteínas (4,4 a 6,8\%) maiores que açúcar e gordura (POWER, 2015). Comparando o cálculo aproximado da proteína das dietas 1 e 2, notou-se que os níveis de proteínas por mamada estão dentro destes parâmetros, 5,10 e $6,76 \%$ respectivamente. Portanto, sugere que estas supriram as exigências proteicas dos filhotes.

A manutenção do trânsito intestinal é fundamental no aleitamento artificial, devido à adaptação a deita, com isso a utilização de mix de fibras em pó se faz necessária. A suplementação mineral e vitamínica é feita de forma empírica, utilizando doses extrapoladas de cães e gatos domésticos. Contudo, esta suplementação deve ser feita com cautela para que 0 animal não apresente algum tipo de doença metabólica por suplementação inadequada (CARCIOFI; OLIVEIRA, 2007). E ainda Miranda (2014) recomenda suplementação de vitamina $\mathrm{K}$ em 5 a 10 mg/ animal por dia.

\section{CONCLUSÃO}

Tendo isso, as dietas fornecidas aos filhotes de tamanduá-bandeira $(M$. tridactyla) foram suficientes para estabelecer um adequado ganho de peso e sem demonstrar sinais clínicos de distúrbios metabólicos. Ainda assim, trabalhos para estabelecer as exigências nutricionais de Pilosa são necessários para a formulação de um sucedâneo mais específico.

\section{REFERÊNCIAS}

CARCIOFI, A. C.; OLIVEIRA, L. D. Doenças Nutricionais. In: CUBAS, Z. S.; SILVA, J. C.;

CATÃO-DIAS, J. L. Tratado de Animais selvagens - medicina veterinária. 1ed. São Paulo: Roca. 2007.

CLARK, A.; SILVA-FLETCHER, A.; FOX, M.; KREUZER, M.; CLAUSS, M. Survey of feeding practices, body condition and faeces consistency in captive ant-eating mammals in the UK. 
Journalof ZooandAquariumResearch. v.4, p.183-195, 2016.

CONGRESSO DA SOCIEDADE DE AQUÁRIOS E ZOOLÓGICOS DO BRASIL, 39., 2015, Foz do Iguaçu.

COSTA, M. E. L. T. Neonatologia de mamíferos. In: CUBAS, Z. S.; SILVA, J. C.; CATÃO-DIAS, J. L. Tratado de Animais selvagens - medicina veterinária. 1ed. São Paulo: Roca. 2007.

MIRANDA, F. Manutenção de Tamanduás em cativeiro. 1ed. São Carlos: Cubo. 2012.

MIRANDA, F. Cingulata (Tatus) e Pilosa (Preguiças e Tamanduás). In: CUBAS, Z. S.; SILVA, J. C.; CATÃO-DIAS, J. L. Tratado de Animais selvagens medicina veterinária. 2ed. São Paulo: Roca. 2014.

NOFS, S. A.; DIERENFELD, E. S. BACKUS, R. C. Effect of increasing taurine and methionine supplementation on urinary taurine excretion in a model insectivore, the giant anteater (Myrmecophagatridactyla). J. Anim, Physiol. Nutri. n. 102, p. 316-325. 2018.

NOWAK, R. M.; PARADISO, J. L. Walker's Mammals of the World. The Johns Hopkins University Press. v. 2, Baltimore. 1983.

POWER, M. L. Nutrient Composition of the milk of the giant anteater (Myrmecophagatridactyla). BISSEL, H.; BROOKS. M. Proceedings of the Eleventh Conference on Zoo and Wildlife Nutrition.AZA NutritionAdvisoryGroup. Disponível em: $<$ https://nagonline.net/4012/nutrientcomposition-milk-giant-anteatermyrmecophaga-tridactyla/> Acesso
STAHL, M.; OSMANN, C.; ORTMANN, S.; KREUZER, M.; HATT, J.-M.; CLAUSS, M. Energy intake for maintenance in a mammal with a low basal metabolism, the giant anteater (Myrmecophagatridactyla). Journal of Physiology and Animal Nutrition. v. 5, n. 96, p. 818-24, 2012.

Agradecemos ao apoio da Fundação Araucária e da Coordenação de Aperfeiçoamento de Pessoal de Nível Superior - CAPES na realização do $3^{\circ}$ Workshop de Nutrição de Animais Selvagens.
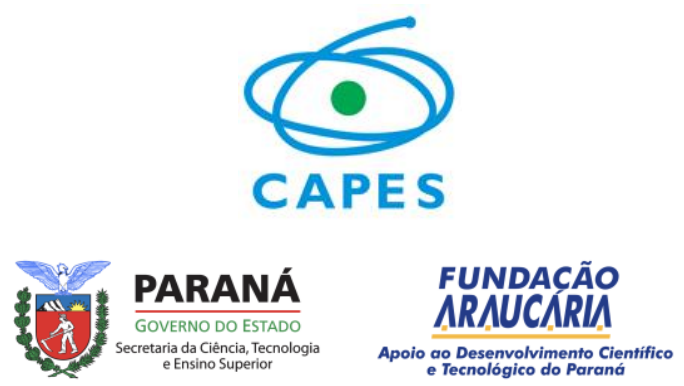

em: 03 set. 2018. 